\title{
Comparison of ruminal lipid metabolism in dairy cows and goats fed diets supplemented with starch, plant oil, or fish oil
}

\author{
P. G. Toral, ${ }^{*} \nmid \ddagger^{1}$ L. Bernard, ${ }^{*} \dagger$ A. Belenguer, $\ddagger$ J. Rouel, ${ }^{*} \dagger$ G. Hervás, $\ddagger$ Y. Chilliard, ${ }^{\star} \dagger$ and P. Frutos $\ddagger$ \\ *INRA, UMR 1213 Herbivores, F-63122 Saint-Genès-Champanelle, France \\ †Clermont Université, VetAgro Sup, UMR Herbivores, BP 10448, F-63000, Clermont-Ferrand, France \\ łInstituto de Ganadería de Montaña (CSIC-ULE), Finca Marzanas s/n, 24346 Grulleros, León, Spain
}

\section{ABSTRACT}

Direct comparison of cow and goat performance and milk fatty acid responses to diets known to induce milk fat depression (MFD) in the bovine reveals relevant species-by-diet interactions in ruminal lipid metabolism. Thus, this study was conducted to infer potential mechanisms responsible for differences in the rumen microbial biohydrogenation $(\mathrm{BH})$ due to diet and ruminant species. To meet this objective, 12 cows and 15 goats were fed a basal diet (control), a similar diet supplemented with $2.2 \%$ fish oil (FO), or a diet containing $5.3 \%$ sunflower oil and additional starch $(+38 \%$; SOS $)$ according to a $3 \times 3$ Latin square design with 25 -d experimental periods. On the last day of each period, fatty acid composition (by gas chromatography) and bacterial community (by terminal-RFLP), as well as fermentation characteristics, were measured in rumen fluid samples. Results showed significant differences in the response of cows and goats to dietary treatments, although variations in some fermentation parameters (e.g., decreases in the acetate-to-propionate ratio due to FO or SOS) were similar in both species. Main alterations in ruminal $\mathrm{BH}$ pathways potentially responsible for MFD on the SOS diet (i.e., the shift from trans-11 to trans-10 18:1 and related increases in trans-10,cis-12 18:2) tended to be more pronounced in cows, which is consistent with an associated MFD only in this species. However, changes linked to FO-induced MFD (e.g., decreases in 18:0 and increases in total trans-18:1) were stronger in caprine rumen fluid, which may explain their unexpected susceptibility (although less marked than in bovine) to the negative effect of FO on milk fat content. Altogether, these results suggest that distinct ruminal mechanisms lead to each type of diet-induced MFD and confirm a pronounced interaction with species. With regard to microbiota,

Received August 20, 2015.

Accepted September 26, 2015.

${ }^{1}$ Corresponding author: pablo.toral@csic.es differences between cows and goats in the composition of the rumen bacterial community might be behind the disparity in the microorganisms affected by the experimental diets (e.g., Ruminococcaceae, Lachnospiraceae, and Succinivibrionaceae in the bovine, and Pseudobutryrivibrio, Clostridium cluster IV, Prevotella, and Veillonellaceae in the caprine), which hindered the assignation of bacterial populations to particular $\mathrm{BH}$ steps or pathways. Furthermore, most relevant variations in microbial groups corresponded to as yet uncultured bacteria and suggest that these microorganisms may play a predominant role in the ruminal lipid metabolism in both cows and goats.

Key words: biohydrogenation, fatty acid, rumen bacteria, milk fat depression

\section{INTRODUCTION}

Milk fat depression (MFD) represents a situation where milk fat concentration and yield can decrease up to $50 \%$, often as a result of changes in diet composition (Bauman and Griinari, 2001; Shingfield et al., 2010a). Inducing MFD might have applications as a management tool in dairy cow farming (Bauman et al., 2011), but has a potential negative effect on the subsequent manufacture of cheese. Although goats were thought, for many years, to be less sensitive to diet-induced MFD (Shingfield et al., 2010a; Toral et al., 2014), more recent studies have demonstrated their susceptibility when fed marine lipids at a high dose $(2.2 \% \mathrm{DM}$; Toral et al., 2015).

The effect of nutrition on milk fatty acid (FA) composition is largely determined by rumen lipid metabolism, particularly by the biohydrogenation $(\mathbf{B H})$ process (AbuGhazaleh et al., 2002; Loor et al., 2005; Toral et al., 2012). Alterations in rumen BH pathways may explain the basis for diet-induced MFD (Bauman and Griinari, 2001), but the underlying mechanisms remain uncertain and might differ depending on factors such as diet or host animal species.

Starting with the diet, despite differences in MFD induced by feeding either marine lipids or high-starch 
rations and plant oils (Chilliard et al., 2007; Shingfield and Griinari, 2007), no direct comparative study exists testing the hypothesis that distinct ruminal mechanisms lead to each type of diet-induced MFD.

Regarding the host animal, interspecies variations in rumen digestion and microbiota (Moon et al., 2010; Lee et al., 2012) are well known in ruminant nutrition. Conversely, knowledge of putative species-specific differences in $\mathrm{BH}$ pathways only arises from indirect comparisons (Loor et al., 2004; Boeckaert et al., 2008; Toral et al., 2012), often by extrapolating data from milk FA, due to the scarcity of available studies on this issue, particularly in the caprine (Chilliard et al., 2014; Li et al., 2014).

Accordingly, a first direct comparison study was performed in cows and goats, both receiving diets known to induce MFD in bovine, to describe milk fat yield and FA composition (Toral et al., 2015). In that study, milk FA profiles showed a significant species by diet interaction in ruminal responses (Toral et al., 2015). Furthermore, the lack of MFD in goats fed a starch-rich diet supplemented with sunflower oil was attributed to a putatively greater stability in $\mathrm{BH}$ pathways compared with cows, whereas the decrease in milk fat content in both species when fed fish oil at $2.2 \%$ DM ( -30 and $-21 \%$ in cows and goats, respectively) was associated with a strong inhibition of ruminal 18:1 saturation (i.e., the same mechanism in cows and goats). Nevertheless, even though the reasons for this interaction are expected to be linked to species differences in the structure and composition of the rumen bacterial community (Moon et al., 2010; Lee et al., 2012), knowledge is still limited on the microbial ecology of FA metabolism, especially in goats (Huws et al., 2011; Toral et al., 2012; Zhu et al., 2012). Additionally, application of culture-independent molecular techniques, including next-generation sequencing methodologies, has revealed that the effect of lipids on bacterial populations remains largely unknown (Castro-Carrera et al., 2014; Huws et al., 2015).

On this basis, a comparative study with lactating cows and goats was undertaken to test the following hypotheses: (1) ruminal mechanisms underlying MFD induced by marine lipid supplements or by diets containing high amounts of starch and plant oils are different, and (2) rumen microbial $\mathrm{BH}$ responses vary between animal species. To meet this objective, cows and goats were fed a basal diet (control), a similar diet supplemented with fish oil (FO), or a diet containing sunflower oil and additional starch (SOS). Then, changes in rumen FA composition, bacterial community, and fermentation characteristics were measured and used to infer potential mechanisms responsible for differences in the regulation of ruminal lipid metabolism due to diet and ruminant species.

\section{MATERIALS AND METHODS}

\section{Animals, Experimental Design, Diets, and Management}

All procedures involving animals were approved by the Animal Care Committee of INRA in accordance with the guidelines established by the European Union Directive 2010/63/EU. Details of the experimental design have been described in Toral et al. (2015). Briefly, 12 multiparous, nonpregnant Holstein cows and 15 multiparous, nonpregnant Alpine goats were allocated to 1 of 3 groups ( 4 cows and 5 goats each) and used in a replicated $3 \times 3$ Latin square to test the effects of 3 treatments during three 25-d experimental periods. Unfortunately, 1 goat had to be withdrawn from the experiment because it suffered diarrhea. All animals were offered grass hay ad libitum supplemented with concentrates containing no additional lipid (control), FO, or SOS. The control concentrate was based on (\% DM) cracked corn grain (54.9), pelleted dehydrated alfalfa (29.4), soybean meal (14.3), and a mineral-vitamin premix (1.4). In the FO and SOS concentrates, both fish oil $(3.6 \% \mathrm{DM})$ and sunflower oil (9.0\% DM) replaced alfalfa pellets on a proportionate basis and were mixed manually with other ingredients immediately before feeding out. The fish oil represented $2.2 \%$ and the sunflower oil $5.3 \%$ of total DMI. The remaining alfalfa pellets and part of the corn grain were replaced by flattened wheat grain $(37.4 \% \mathrm{DM})$ in SOS concentrate. Hay refusals were weighed daily and used to adjust the amounts of concentrate offered the following day to maintain the targeted dietary forage to concentrate ratio (40:60 on a DM basis). Diets were offered as 2 equal meals at 0830 and 1600 h. Formulation, chemical composition, and FA profile of the concentrates and hay have been reported previously (Toral et al., 2015). Experimental diets were formulated to be isoproteic $(139 \mathrm{~g}$ of $\mathrm{CP} / \mathrm{kg}$ of DM), and the mean starch concentrations (values for the control, FO, and SOS diets, respectively) were 232, 239 , and $325 \mathrm{~g} / \mathrm{kg}$ of DM and those of NDF were 365 , 349 , and $296 \mathrm{~g} / \mathrm{kg}$ of DM. Fish oil and sunflower oil supplied 400 and $953 \mathrm{~g}$ of FA/d in cows and 48 and 114 $\mathrm{g}$ of $\mathrm{FA} / \mathrm{d}$ in goats, respectively. Animals had access to a constant supply of fresh water and were milked at 0800 and $1530 \mathrm{~h}$.

\section{Rumen Sample Collection}

On d 25 of each experimental period, rumen fluid was collected by stomach tube from each animal after an overnight period without concentrate distribution (but with ad libitum access to hay) and before morning feeding. This technique has been validated as a 
feasible alternative to surgical rumen cannulation for obtaining representative rumen samples to examine diet and ruminant species effects (Ramos-Morales et al., 2014). Immediately after collection, the fluid was carefully checked to ensure that no saliva was present and strained through a nylon membrane $(500 \mu \mathrm{m}$; Dominique Dutscher, Brumath, France). Then, the $\mathrm{pH}$ was measured, and a 4-mL subsample was acidified with $4 \mathrm{~mL}$ of $0.2 \mathrm{M} \mathrm{HCl}$ for ammonia determinations. Further 0.8-mL aliquots of strained ruminal fluid were taken for VFA analysis (deproteinized with $0.5 \mathrm{~mL}$ of $20 \mathrm{~g} / \mathrm{L}$ metaphosphoric and $4 \mathrm{~g} / \mathrm{L}$ of crotonic acids in $0.5 \mathrm{M} \mathrm{HCl}$ ). All these samples were stored at $-30^{\circ} \mathrm{C}$ until analysis. Additional subsamples (approximately $80 \mathrm{~mL}$ ) of rumen fluid were also collected, immediately frozen at $-80^{\circ} \mathrm{C}$, freeze-dried, and stored at $-80^{\circ} \mathrm{C}$ until analyzed for FA composition and bacterial community.

\section{Chemical Analysis}

Ruminal Fermentation Characteristics. Ammonia concentration was determined by colorimetric methods and VFA by GC, using crotonic acid as an internal standard (Frutos et al., 2004).

Fatty Acid Composition. Lipid in $200 \mathrm{mg}$ of freeze-dried rumen fluid was extracted using a mixture of hexane and isopropanol $(3: 2, \mathrm{vol} / \mathrm{vol})$ and converted to FAME by sequential base-acid catalyzed transesterification (Toral et al., 2010), using cis-12 13:1 as an internal standard (Larodan Fine Chemicals AB, Malmö, Sweden). The FAME recovered were quantified using a GC (Agilent 7890A GC System, Santa Clara, CA) equipped with a flame-ionization detector and a 100-m fused silica capillary column $(0.25 \mathrm{~mm}$ i.d., $0.2-$ $\mu \mathrm{m}$ film thickness; CP-SIL 88, CP7489, Varian Ibérica S.A., Madrid, Spain) and hydrogen as the carrier gas $(207 \mathrm{kPa}, 2.1 \mathrm{~mL} / \mathrm{min})$. Total FAME profile in a $2-\mu \mathrm{L}$ sample volume at a split ratio of 1:50 was determined using a temperature gradient program (Shingfield et al., 2003). Isomers of 18:1 were further resolved in a separate analysis under isothermal conditions at $170^{\circ} \mathrm{C}$ (Shingfield et al., 2003). Peaks were identified based on retention time comparisons with commercial authentic standards (Nu-Chek Prep., Elysian, MN; SigmaAldrich, Madrid, Spain; and Larodan Fine Chemicals $\mathrm{AB})$, cross referencing with chromatograms reported in the literature (Shingfield et al., 2003; Toral et al., 2010) and comparison with reference samples for which the FA composition was determined based on GC analysis of FAME and GC-MS analysis of corresponding 4,4-dimethyloxazoline derivatives (Toral et al., 2010).

Bacterial Community. Freeze-dried samples of rumen fluid were thoroughly homogenized and, within each period and species, mixed per dietary group before
DNA extraction (Belenguer et al.., 2010), which led to 6 samples per experimental diet and 9 samples per species. The DNA was extracted twice from each sample, and duplicates were combined and used as templates for terminal-RFLP (T-RFLP) analysis of bacterial $16 \mathrm{~S}$ rRNA genes. Concentrations of DNA were determined by spectrophotometry (NanoDrop ND-1000 Spectrophotometer, Nanodrop Technologies, Wilmington, DE). The T-RFLP analysis was performed using a universal bacteria-specific primer pair set and 3 restriction enzymes (HhaI, MspI, and HaeIII; Belenguer et al., 2010). The lengths of the fluorescently labeled terminal restriction fragments $(\mathbf{T}-\mathbf{R F})$ were determined with the size standard ET-900-R (GE Healthcare Life Sciences, Buckinghamshire, UK) using the GeneMarker Analysis software (SoftGenetics, State College, PA).

Data from T-RFLP (size, base pairs, and peak area for each T-RF) were analyzed for peak filtering and binning, as outlined by Abdo et al. (2006), and used to determine the relative abundance of each fragment over the total peak area as well as the diversity indices (number of T-RF or richness, and Shannon-Wiener and Shannon evenness indices; Hill et al., 2003). In silico restriction for the major rumen bacteria with the primers and enzymes used in the analysis, obtained from the Ribosomal Database Project II Website (http://rdp. cme.msu.edu/index.jsp; Cole et al., 2014), was used to infer the potential bacterial composition of rumen fluid.

\section{Statistical Analysis}

Fermentation and FA data were subjected to ANOVA for a $3 \times 3$ Latin square design (Kaps and Lamberson, 2009) using the MIXED procedure of the SAS (version 9.4, SAS Institute Inc., Cary, NC). The statistical model included the fixed effects of period, species $(\mathbf{S p})$, experimental diet $(\mathbf{D})$, the interaction $\mathrm{Sp}$ $\times \mathrm{D}$, the order in which treatments were allocated to each animal, and the random effect of animal nested within treatment order. For FA found exclusively in the rumen fluid of cows and goats fed the FO treatment, the fixed effects due to diet and diet by species interaction were removed. For relative abundances of each T-RF, the group (4 cows or 5 goats), instead of the animal, was considered the experimental unit (18 data per T-RF: 2 species $\times 3$ diets $\times 3$ periods). Because some of these T-RFLP results did not satisfy the assumptions of normality, data were transformed to $\log _{10}(\mathrm{n}+\mathrm{c})$ before analysis. The constant $(\mathrm{c})$ was used to avoid mathematically undefined computations in T-RF with zero values and was of the same order of magnitude as the variable (i.e., average value of relative abundances for each T-RF). The CORR procedure was used to generate Pearson correlation coefficients 
between rumen and milk FA percentages and milk fat content in the same animals, derived from Toral et al. (2015). Differences were declared significant at $P<$ 0.05 and considered a trend toward significance at $P<$ 0.10 . Means were separated through the pdiff option of the lsmeans statement of the MIXED procedure, and least squares means are reported.

Hierarchical clustering analysis with Ward's method based on Bray-Curtis distances was performed with R-project software (www.r-project.org, version 2.13.1) to build a dendrogram with relative abundance data derived from T-RFLP (T-RF). Distance-based permutational multivariate ANOVA (Anderson, 2001) of the same data was conducted, using the PERMANOVA software (version 1.6), to assess the effect of diet, species, and their interaction on the whole-rumen bacterial structure.

\section{RESULTS}

\section{Rumen Fermentation Characteristics}

The 2 ruminant species showed significant differences in rumen fermentation characteristics (Table 1). Thus, although the ammonia concentration was approximately twice higher in goats than in cows $(P<0.001)$, that of total VFA was $22 \%$ lower in caprine rumen fluid $(P$ $<0.01)$. The molar proportion of acetate was slightly greater in the bovine $(P<0.001)$, whereas the converse was observed for the other reported VFA $(P<0.001$ for propionate and minor VFA, and $P<0.10$ for butyrate).

In both species, ammonia concentration was decreased with SOS $(P<0.001)$, which also lowered that of total VFA when compared with the control $(P<0.05)$. Slight reductions in the molar proportion of acetate were also observed in FO and SOS in comparison with the control $(P<0.001)$, whereas propionate increased, particularly in goats offered the SOS diet (interaction
Sp $\times \mathrm{D} ; P<0.05)$. Acetate-to-propionate ratio was reduced to the same extent in cows and goats on the SOS and, less markedly, on the FO diet $(P<0.001)$. Decreases in butyrate concentrations with SOS feeding also tended to be more pronounced in caprine rumen fluid (interaction $\mathrm{Sp} \times \mathrm{D} ; P<0.10$ ), but no difference between species was found for the concomitant increase in minor VFA $(P<0.001)$. The rumen $\mathrm{pH}$, measured before morning feeding, was marginally higher in SOS (mean value of 7.12 for control and FO vs. 7.28 for SOS; $P<0.01$; data not shown in tables).

\section{Fatty Acid Concentrations in the Rumen Fluid}

The concentration of total FA was higher in the rumen fluid of goats $(P<0.001$; Table 2$)$, and increments due to SOS were significantly greater in this species than in the bovine (156 vs. $63 \%$, respectively; $P<$ 0.001 for the interaction $\mathrm{Sp} \times \mathrm{D}$ ); these differences mirrored and were mainly due to those of SFA. In general, diet-induced variations in the major FA groups in the rumen were also more pronounced in goats than in cows (interaction $\mathrm{Sp} \times \mathrm{D} ; P<0.01$ ), with the exception of the increase in total PUFA after FO supply $(P$ $<0.001$ ), which was similar in both species (interaction $\mathrm{Sp} \times \mathrm{D} ; P>0.10$ ).

Supplemented diets resulted in substantial variations in the concentration of individual FA, with numerous Sp $\times$ D interactions. The saturated 18:0 and 16:0 were the most abundant FA in the rumen fluid of both cows and goats fed the control diet; they were greater in goats when expressed in grams per kilogram of DM $(P<0.001)$, but 18:0 was similar in percent of total FA $(P>0.10 ;$ Supplemental Table S1; http://dx.doi. org/10.3168/jds.2015-10292). These FA were differently altered by FO and SOS diets $(P<0.001$; Table 2$)$. The amount of 16:0 increased with FO in both species, and to a minor extent with SOS in goats when expressed

Table 1. Effect of dietary supplements of fish oil or sunflower oil and starch on ruminal fermentation characteristics in cows and goats ${ }^{1}$

\begin{tabular}{|c|c|c|c|c|c|c|c|c|c|c|}
\hline Item & \multicolumn{3}{|c|}{ Cows } & \multicolumn{3}{|c|}{ Goats } & SEM & \multicolumn{3}{|c|}{$P$-value ${ }^{2}$} \\
\hline Ammonia (mg/L) & 70.6 & 75.9 & 34.1 & 146.8 & 140.2 & 75.6 & 8.25 & $<0.001$ & $<0.001$ & 0.091 \\
\hline Acetate & 70.83 & 68.63 & 68.62 & 66.90 & 64.02 & 62.37 & 0.687 & $<0.001$ & $<0.001$ & 0.208 \\
\hline Propionate & $14.56^{\mathrm{d}}$ & $16.37^{\mathrm{c}}$ & $18.97^{\mathrm{b}}$ & $15.08^{\mathrm{cd}}$ & $18.73^{\mathrm{b}}$ & $22.84^{\mathrm{a}}$ & 0.642 & $<0.001$ & $<0.001$ & 0.026 \\
\hline Acetate:propionate & 4.96 & 4.26 & 3.67 & 4.52 & 3.46 & 2.79 & 0.158 & $<0.001$ & $<0.001$ & 0.258 \\
\hline
\end{tabular}

\footnotetext{
${ }^{\mathrm{a}-\mathrm{d}}$ Within a row, different superscripts indicate significant differences $(P<0.05)$ due to the effect of $\mathrm{Sp} \times \mathrm{D}$.

${ }^{1}$ Control $=$ basal diet containing no additional oil; FO = diet supplemented with fish oil; SOS = diet containing sunflower oil and wheat starch

${ }^{2}$ Probability of significant effects due to species (Sp), experimental diet (D), and their interaction $(\mathrm{Sp} \times \mathrm{D})$.

${ }^{3}$ Calculated as the sum of isobutyrate, valerate, isovalerate, and caproate.
} 


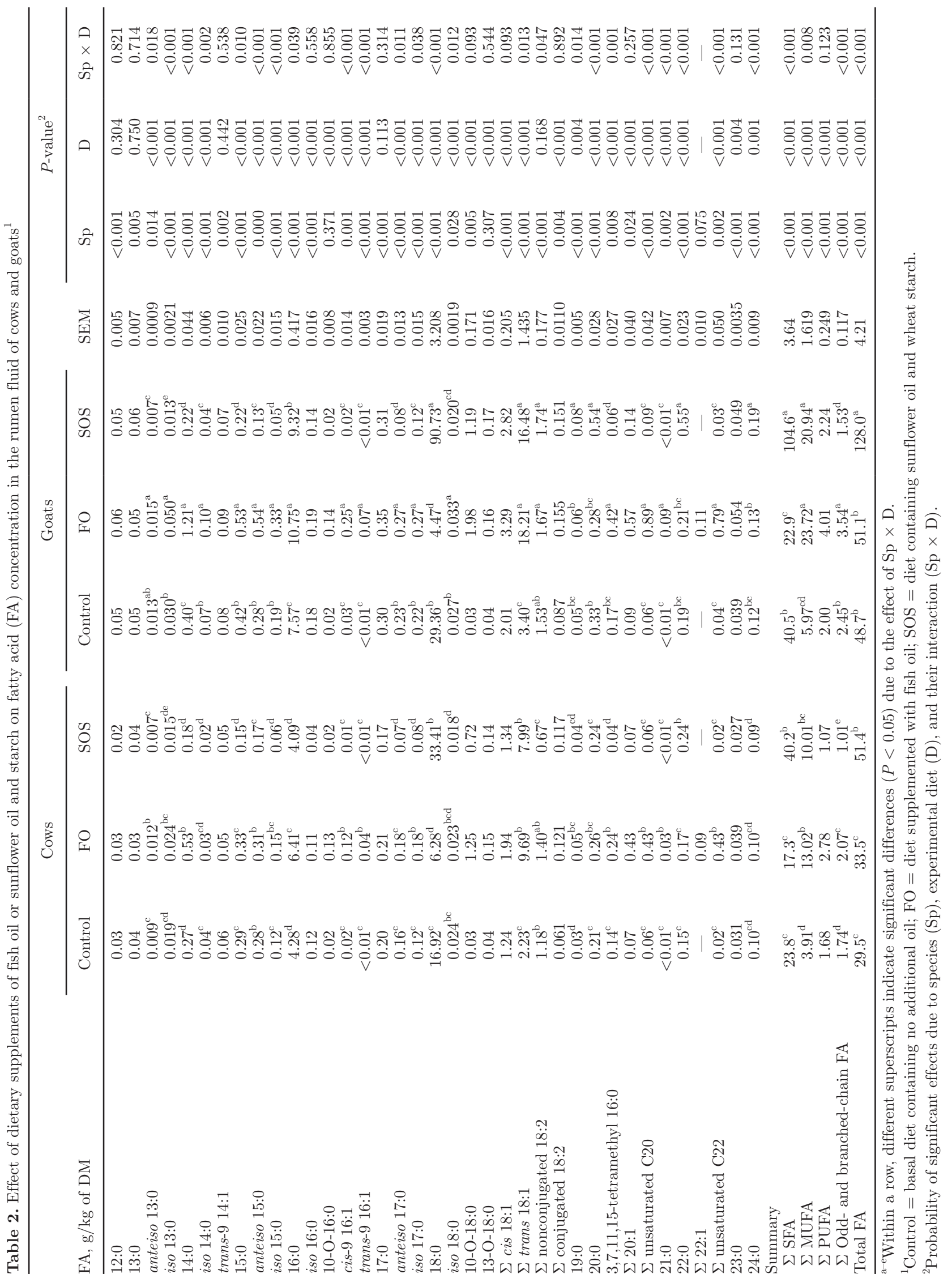


in grams per kilogram of $\mathrm{DM}$ (interaction $\mathrm{Sp} \times \mathrm{D} ; P$ $<0.05)$, although it decreased with SOS and more markedly in goats when expressed as a percent of total FA (Supplemental Table S1). Concerning the 18:0, FO lowered its concentration in the rumen, but the proportionate decrease was greater in goats compared with cows ( -85 vs. $-63 \%$, respectively). On the other hand, SOS increased by 2 and 3 fold the concentration of this FA in bovine and caprine rumen fluids, respectively (interaction $\mathrm{Sp} \times \mathrm{D} ; P<0.001$ ). The sum of odd- and branched-chain fatty acids (OBCFA) was augmented by $\mathrm{FO}$ in both species (more markedly in goats; $P$ $<0.001$ for the interaction $\mathrm{Sp} \times \mathrm{D})$, whereas SOS negatively affected their content. Although this general pattern was consistent for most individual OBCFA in goats, numerical differences did not always attain statistical significance in cows (Table 2). In addition, interspecies dissimilarities in OBCFA were observed in animals fed the control diet, both when concentrations were expressed as grams per kilogram of DM (e.g., iso 13:0, iso 14:0, 15:0, and anteiso 15:0; Table 2) and as a percent of total FA (e.g., 15:0, anteiso 15:0, 17:0, and iso 18:0; Supplemental Table S1). Regarding oxygenated FA, the highest concentrations of 10-O-16:0 and 10-O-18:0 in the rumen fluid were detected in FO $(P$ $<0.001$ ), with a tendency toward greater increases of 10-O-18:0 in goats (interaction $\mathrm{Sp} \times \mathrm{D} ; P<0.10$ ). Although SOS also favored the accumulation of this keto acid $(P<0.001)$, no differences due to animal species were observed. Lipid supplemented diets similarly increased 13-O-18:0 in the rumen of cows and goats $(P$ $<0.001)$.

The abundance of identified MUFA was significantly affected by the experimental diets, with the exception of trans-9 14:1. Addition of FO led to the highest ( $P$ $<0.05$ ) content of $16: 1,20: 1,23: 1$, and 24:1 intermediates in the rumen, whereas increments in the sum of trans 18:1 isomers were comparable for both FO and SOS and 22:1 was detected only in FO (Tables 2 and $3)$. For all these MUFA, the response of goats was more pronounced than that of cows (interaction $\mathrm{Sp} \times$ $\mathrm{D} ; P<0.05)$. As shown in Table 3, trans-11 18:1 was the most abundant MUFA in the control diet and its concentration augmented by 5.4 and 7.8 times, respectively, in cows and goats fed FO $(P<0.001)$. On the other hand, with SOS feeding, trans-10 18:1 expressed as a percent of total FA or as grams per kilogram of DM became the major trans FA in cows $(P<0.001)$ and reached similar concentrations to trans-11 18:1 in goats (Table 3 and Supplemental Table S1; http:// dx.doi.org/10.3168/jds.2015-10292), whereas a high interindividual variation precluded significant increases caused by FO, except for a significant increase in cows when expressed as a percent of total FA. The amount of other trans 18:1 isomers was often greater in the SOS treatment, particularly in goats $(P<0.05)$, although trans-9 and trans-12 18:1 were similarly affected by FO and SOS treatments. Fish oil enhanced $(P<0.05)$ the abundance of cis-9 18:1 and cis-11 18:1, with increases in the latter being highest in the caprine $(P<0.001$ for the interaction $\mathrm{Sp} \times \mathrm{D}$ ).

The concentration of 18:2 isomers varied substantially across diets and species (Table 3 ). The content of 18:2n-6 was lowered in cows on SOS and in goats on FO treatment $(P<0.05)$; on the contrary, FO favored the rumen accumulation of other nonconjugated 18:2, such as cis-9,trans-12 18:2, trans-9,cis-12 18:2, trans-11,cis-15 18:2, trans-9,trans-12 18:2, and trans11,trans-15 18:2 in both species $(P<0.05)$. The rumen fluid of cows on the SOS treatment tended to have the highest amount of trans-10,cis-12 CLA $(P<0.10$ for the interaction $\mathrm{Sp} \times \mathrm{D})$, an isomer that was increased to a minor extent in response to FO. Furthermore, the concentration (expressed as $\mathrm{g} / \mathrm{kg}$ of DM) of trans- 9 , cis- 11 CLA augmented in FO compared with the other diets $(P<0.001)$, whereas cis-9, trans-11 CLA was not significantly affected by the experimental diets $(P>0.10$; Table 3). However, cis-9,trans-11 CLA expressed as a percent of total FA (Supplemental Table S1; http:// dx.doi.org/10.3168/jds.2015-10292) was increased in cows fed FO and decreased in goats fed SOS. The accumulation of trans, trans CLA with supplemented diets was significantly greater in goats (interaction $\mathrm{Sp} \times \mathrm{D}$; $P<0.01$ ). Trans-10, cis-12 CLA (\% total FA) was increased in cows by both lipid supplements, but not in goats (Supplemental Table S1). With the control diet, no interspecies differences were noted in 18:2n-6 and CLA isomers when expressed as a percent of total FA, including cis-9,trans-11 CLA, whereas the 18:3n-3 percentage was lower in goats than in cows (Supplemental Table S1). For both species, the lowest amount of 18:3n-3 was detected in SOS, but decreases of smaller extent were also found when feeding FO $(P<0.001$; Table 3). Finally, FO increased the concentration of all 20- and 22-carbon PUFA identified in the rumen fluid (Table 3), but most of their concentrations were close or below detection limits in the control and SOS animals (e.g., 20:3n-3, 20:5n-3, 22:4n-6, 22:5n-6, 22:5n-3, and 22:6n-3). These FA were often more abundant in goats $(P<0.10)$, although differences generally disappeared when values were expressed as a percent of total FA (Supplemental Table S1).

\section{Bacterial Community Analysis by T-RFLP}

Regardless of the experimental diet and the species, rumen bacterial T-RFLP analysis generated, on average, $102.7 \pm 3.03,54.9 \pm 4.36$, and $100.6 \pm 3.68$ 
fragments with the enzymes HhaI, MspI, and HaeIII, respectively. Results of the hierarchical clustering and PERMANOVA analyses indicated an effect of animal species on the bacterial structure $(P<0.01)$, with most ruminal fluid samples of the same species being allocated in the same cluster (Figure 1).Within each species, certain segregation by diet was clearer detected in goats $(P<0.10)$, especially due to the SOS treatment (Figure 1).

The diversity indices (Table 4) did not differ between ruminant species, with the exception that the Shannon evenness estimated with HaeIII was greater in cows $(P$ $<0.05$ ). Concerning the effect of diet, both FO and SOS seemed to reduce bacterial diversity, given that indices were numerically lower in many cases, although this was only significant for the Shannon-Wiener index with HhaI and the Shannon evenness with HaeIII. Moreover, an interaction was detected for the latter index with $M s p \mathrm{I}(P<0.05)$, with lower values in goats fed SOS and in cows fed FO.

Differences between ruminant species were also observed in the relative frequency of many $\mathrm{T}-\mathrm{RF}$, but only a few that might be potentially related to the changes detected in the rumen FA profile are shown in Table 5. Once again, the effect of diet varied with the animal species, which was reflected in significant interactions. For instance, the SOS diet induced an increased relative frequency of fragments compatible with species of Succinivibrionaceae (220 bp with HhaI, 492 with MspI and 202 with HaeIII), Ruminococcaceae (554 bp with HhaI and 284 with MspI), and Lachnospiraceae (149 with MspI) only in cows (interaction $\mathrm{Sp} \times \mathrm{D} ; P<$ 0.10), whereas others that may correspond to Pseudobutyrivibrio (190 bp with HhaI and 315 with $M s p I$ ) and Prevotella (102 bp with HhaI, and 162 and 266 with HaeIII) were stimulated with the same diet in goats (interaction $\mathrm{Sp} \times \mathrm{D} ; P<0.10$ ). Terminal-restriction fragments potentially derived from other species of Succinivibrionaceae (495 with MspI) and Clostridium cluster IV (269 with $M s p$ I) were greater with the FO diet in cows and goats, respectively $(P<0.05)$. Fragments putatively assigned to bacteria of the family Veillonellaceae (98 bp with HhaI, 150+268 with MspI, and $244+287$ with HaeIII) only changed significantly in goats, with values being favored by FO and SOS treatments $(P<0.05)$. A similar effect was observed in T-RF that might match with unclassified species of Clostridia (389 bp with HhaI, 70 with MspI, and 262 with $\mathrm{HaeIII)}$ in both ruminant species.

\section{DISCUSSION}

Nutritional strategies for modulating milk FA profile may cause alterations in microbial FA metabolism that, in certain cases, promote the formation of rumen $\mathrm{BH}$ intermediates with antilipogenic effects that can impair milk fat synthesis (Bauman and Griinari, 2001; Shingfield et al., 2010a). In most cases, candidate inhibitors have been initially identified from variations in their milk concentrations and corresponding changes in milk fat content. However, to date, only a few of these $\mathrm{BH}$ metabolites have been associated with diet-induced MFD (such as trans-10 18:1, trans-10,cis-12 CLA, or trans-9,cis-11 CLA; Shingfield and Griinari, 2007; Bauman et al., 2011) and, therefore, discussion of results will be focused on these intermediates and a selected number of other FA that may also be related to reductions in milk fat.

Direct comparison of cow and goat performance and responses to FO and SOS treatments (with mean milk fat contents of 3.34 vs. 3.11 for control, 2.34 vs. 2.47 for FO, and 2.29 vs. 2.90 for SOS in cows and goats, respectively; Toral et al., 2015) suggests interspecies differences in mammary lipogenesis. Furthermore, differences in milk FA composition in the 2 ruminant species in response to FO or SOS diets (e.g., lower trans-10 18:1-to-trans-11 18:1 ratios in goats than in cows; Toral et al., 2015) would point to a relevant role of ruminal $\mathrm{BH}$ pathways, which appear to be more stable and less prone to diet-induced shifts toward the formation of potential inhibitors of milk fat synthesis, such as trans-10 containing intermediates, in goats compared with cows (Chilliard et al., 2014).

In addition, examining together the associated changes in rumen FA concentrations and bacterial community could contribute to improve our knowledge of the microbiology of lipid metabolism and infer potential microorganisms involved in ruminal BH. However, divergences detected in the response of the bacterial populations of cows and goats to dietary treatments, which may be linked to functional differences in their gastrointestinal system (Ley et al., 2008), substantially hinders the assignation of bacterial groups to different lipid metabolic pathways.

\section{Ruminal Fermentation}

One of the earliest theories to explain diet-induced MFD in cows, based on the reduction in the ruminal production of acetate and butyrate and the increase in that of propionate, attributed this syndrome to an inadequate supply of lipid precursors for mammary lipogenesis. However, subsequent studies offered little support for this hypothesis (Bauman and Griinari, 2001). In line with this, the observed decrease in the molar ratio of acetate to propionate in cows and goats fed SOS was not accompanied by MFD in the caprine, whereas both species showed moderate reductions in 


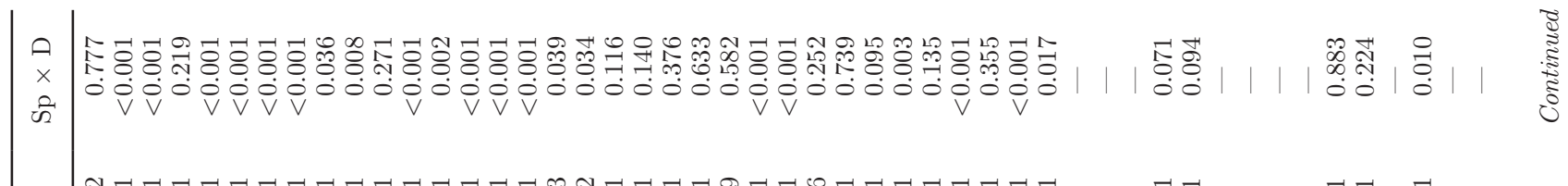

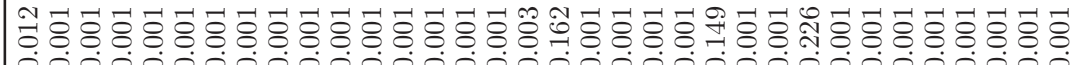

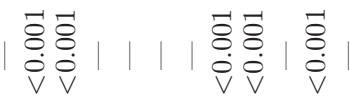

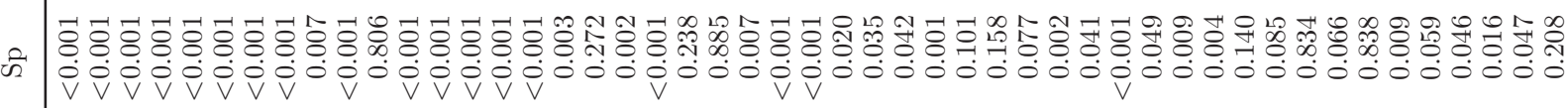

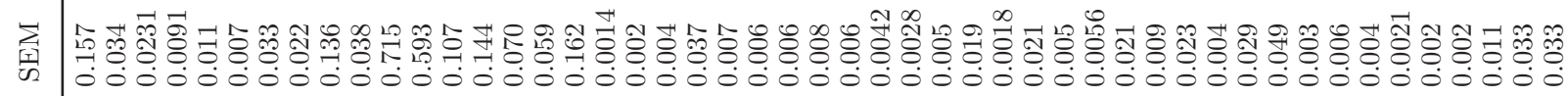

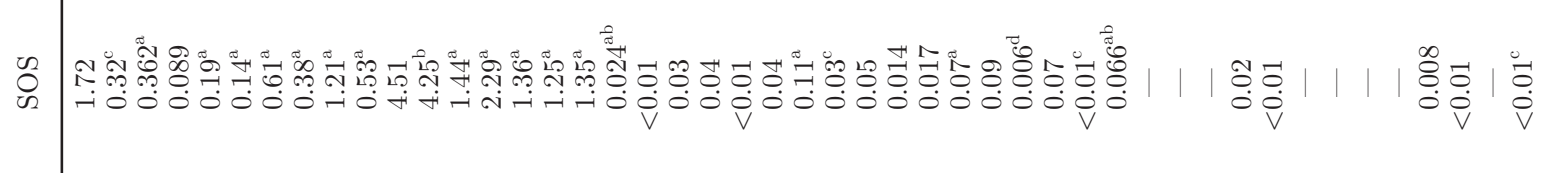

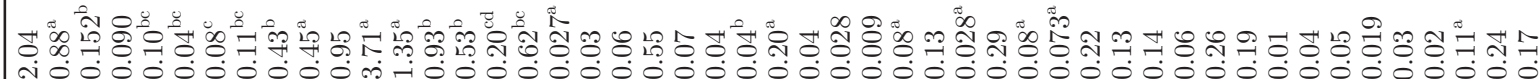

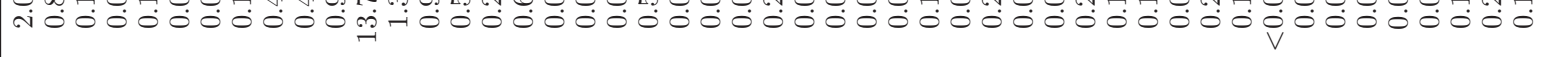

نे

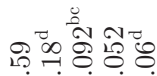

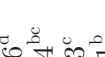

Lre

$\rightarrow$

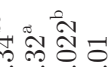

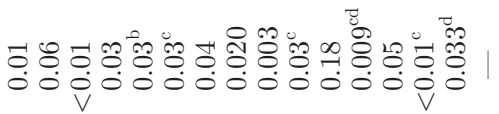

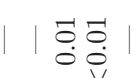

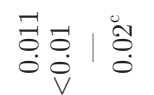

20

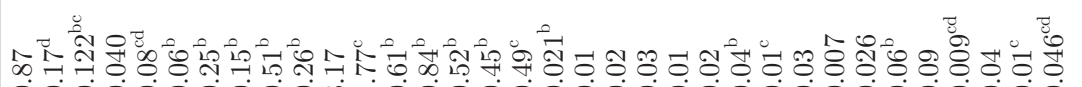

象

0.000

○ं

oo

$\rightarrow \circ$

0000

$\mathrm{V}$

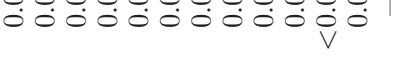

$|\vec{a} \dot{0} \dot{0} \overrightarrow{\dot{\theta}}|$

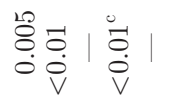

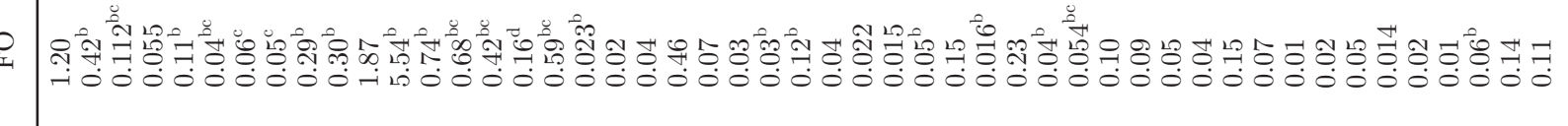

(1)

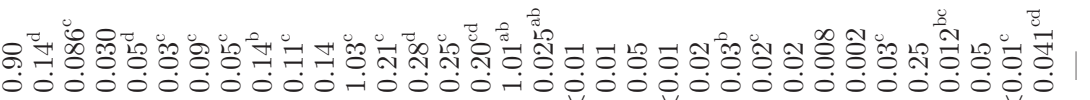

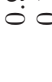


this ratio and a decrease in milk fat content with FO (Toral et al., 2015). Similar shifts in the acetate-to-propionate ratio have been reported when feeding fish oil (Doreau and Chilliard, 1997; Shingfield et al., 2010b) or medium to high levels of sunflower oil ( $>4 \%$; Shingfield et al., 2008; Zened et al., 2013a). In addition, the low NDF and high-starch content of the SOS diet might have contributed to decrease the acetate-to-propionate ratio through potentially negative effects on the abundance of cellulolytic bacteria (Beauchemin et al., 2008). Indeed, iso FA, which have been suggested as biomarkers of these microorganisms (Fievez et al., 2012), were reduced with the SOS diet. With regard to changes in specific bacterial groups, increased molar proportion of propionate with SOS might be related to variation in Succinivibrionaceae species in cows, some of which form succinate, a precursor of propionate (Russell and Hespell, 1981), and of Prevotella strains that promote propionate production (Bekele et al., 2010) in goats.

In both species, feeding SOS decreased the molar proportion of butyrate and the total concentration of VFA in the rumen fluid. Even though other assays in cattle fed plant oils or high-concentrate diets have shown decreases, no effects, and even increases in total VFA and butyrate (e.g., Bateman and Jenkins, 1998; Shingfield et al., 2008; Fuentes et al., 2009), the present results may reflect the combined effects of the high levels of starch and sunflower oil, given the importance of the basal diet on rumen fermentation parameters (Zened et al., 2013a; Ramos-Morales et al., 2014). Lower total VFA concentration for both species with SOS might indicate decreases in either fermentation activity or microbial biomass (Fievez et al., 2012), which for the latter would be supported by reduced OBCFA concentration in the rumen fluid and milk fat (Toral et al., 2015) with the SOS diet. In any case, total VFA concentrations could also be explained by a potential interaction between diet and sampling time, reflecting a greater decrease in the fermentation substrate in the high-starch diet after the overnight period without concentrate distribution (Ramos-Morales et al., 2014).

Ammonia concentration was also lowered with SOS, which is consistent with other findings for high-starch diets or sunflower oil supplements (Shingfield et al., 2008; Fuentes et al., 2009). Ammonia concentration was about 2-fold greater in goats compared with cows, which could be related to differences in bacterial biomass or activity among species, which would need to be further explored. Although ruminal concentrations seem quite limited in cows, particularly with SOS, the calculated protein balance in the same animals was always positive and no differences in milk protein concentration and yield were observed (Toral et al., 2015). Low concentrations might then be explained, at least 


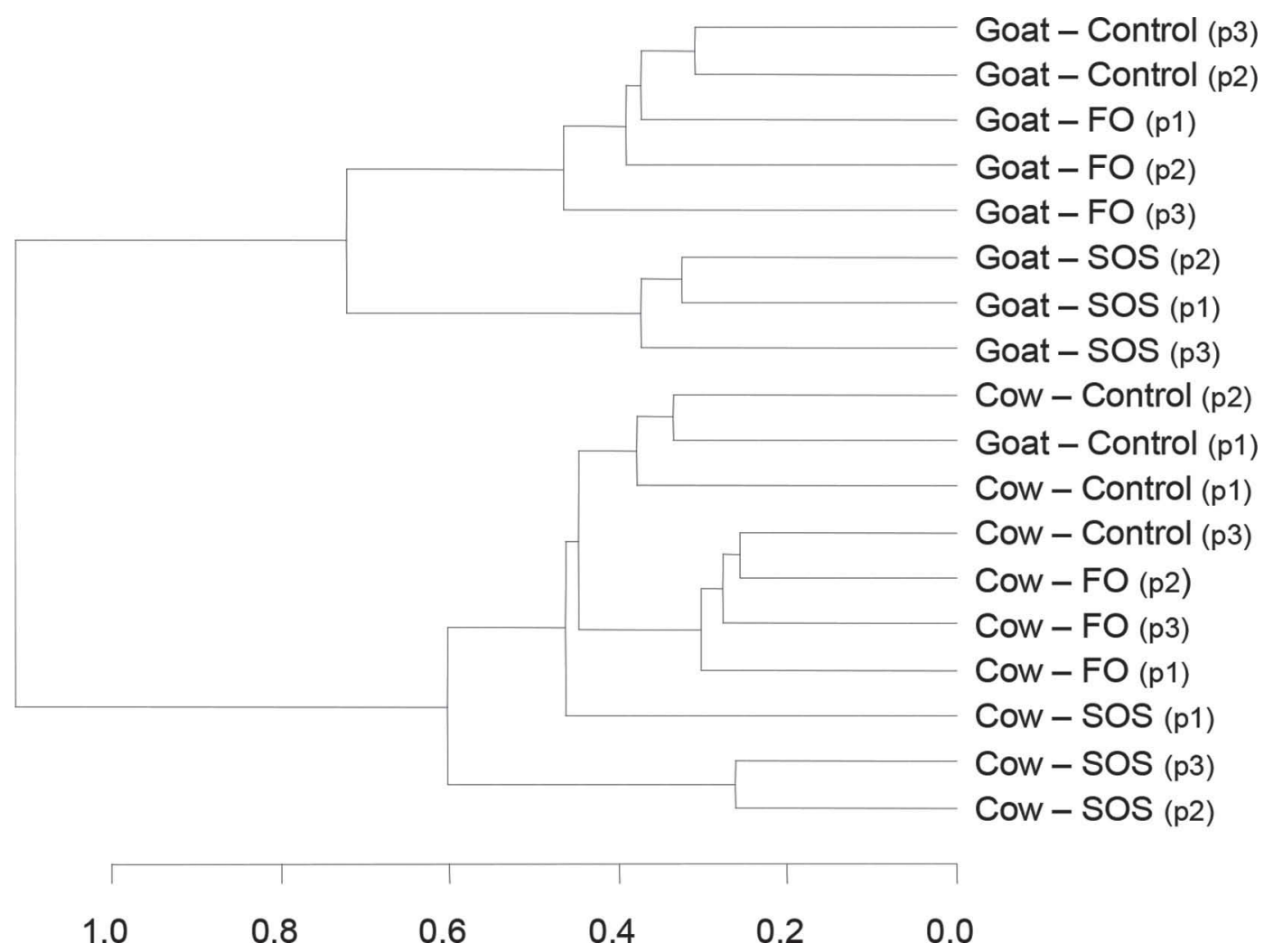

Figure 1. Dendrograms of terminal restriction fragment length polymorphism (T-RFLP) profiles, based on Ward's method and the BrayCurtis distances, of total bacteria in the rumen fluid of cows and goats fed a diet containing no additional oil (control), supplemented with fish oil (FO), or containing sunflower oil and wheat starch (SOS). The experimental period is indicated in parentheses.

to some extent, by the sampling time (after an overnight fast; Ramos-Morales et al., 2014), which could also explain the high ruminal $\mathrm{pH}$. In this regard, $\mathrm{pH}$ values have been shown to be greater when rumen fluid is collected by stomach tube, but this does not preclude from detecting potential diet-induced effects (RamosMorales et al., 2014). In any event, the marginal differences in preprandial $\mathrm{pH}$ with the SOS diet would probably have no biological relevance, because $\mathrm{pH}$ is known to vary largely after meal intake.

Table 4. Effect of dietary supplements of fish oil or sunflower oil and starch on diversity indices (richness, R; Shannon-Wiener, H; Shannon evenness, E) of bacterial communities in the rumen fluid of cows and goats ${ }^{1}$

\begin{tabular}{|c|c|c|c|c|c|c|c|c|c|c|c|}
\hline \multirow{2}{*}{$\begin{array}{l}\text { Restriction } \\
\text { enzyme }\end{array}$} & \multirow[b]{2}{*}{ Index } & \multicolumn{3}{|c|}{ Cows } & \multicolumn{3}{|c|}{ Goats } & \multirow[b]{2}{*}{ SEM } & \multicolumn{3}{|c|}{$P$-value ${ }^{2}$} \\
\hline & & Control & FO & SOS & Control & FO & SOS & & $\mathrm{Sp}$ & $\mathrm{D}$ & $\mathrm{Sp} \times \mathrm{D}$ \\
\hline & $\mathrm{H}$ & 3.77 & 3.64 & 3.68 & 3.86 & 3.69 & 3.47 & 0.066 & 0.726 & 0.017 & 0.089 \\
\hline & $\mathrm{E}$ & 0.81 & 0.79 & 0.83 & 0.82 & 0.79 & 0.75 & 0.018 & 0.391 & 0.328 & 0.078 \\
\hline \multirow[t]{2}{*}{ MspI } & $\mathrm{R}$ & 57.7 & 64.7 & 43.7 & 59.0 & 53.0 & 51.3 & 13.00 & 0.959 & 0.399 & 0.562 \\
\hline & $\mathrm{H}$ & 3.50 & 3.42 & 3.11 & 3.47 & 3.20 & 2.98 & 0.194 & 0.595 & 0.086 & 0.821 \\
\hline & $\mathrm{H}$ & 3.83 & 3.76 & 3.85 & 3.92 & 3.83 & 3.65 & 0.099 & 0.921 & 0.379 & 0.217 \\
\hline & $\mathrm{E}$ & 0.86 & 0.83 & 0.83 & 0.85 & 0.81 & 0.80 & 0.007 & 0.014 & 0.001 & 0.597 \\
\hline
\end{tabular}

\footnotetext{
${ }^{\mathrm{a}-\mathrm{c}}$ Within a row, different superscripts indicate significant differences $(P<0.05)$ due to the effect of $\mathrm{Sp} \times \mathrm{D}$.

${ }^{1}$ Control = basal diet containing no additional oil; FO = diet supplemented with fish oil; SOS = diet containing sunflower oil and wheat starch. For each experimental diet and species, $\mathrm{n}=3$.

${ }^{2}$ Probability of significant effects due to species (Sp), experimental diet (D), and their interaction (Sp $\left.\times \mathrm{D}\right)$.
} 


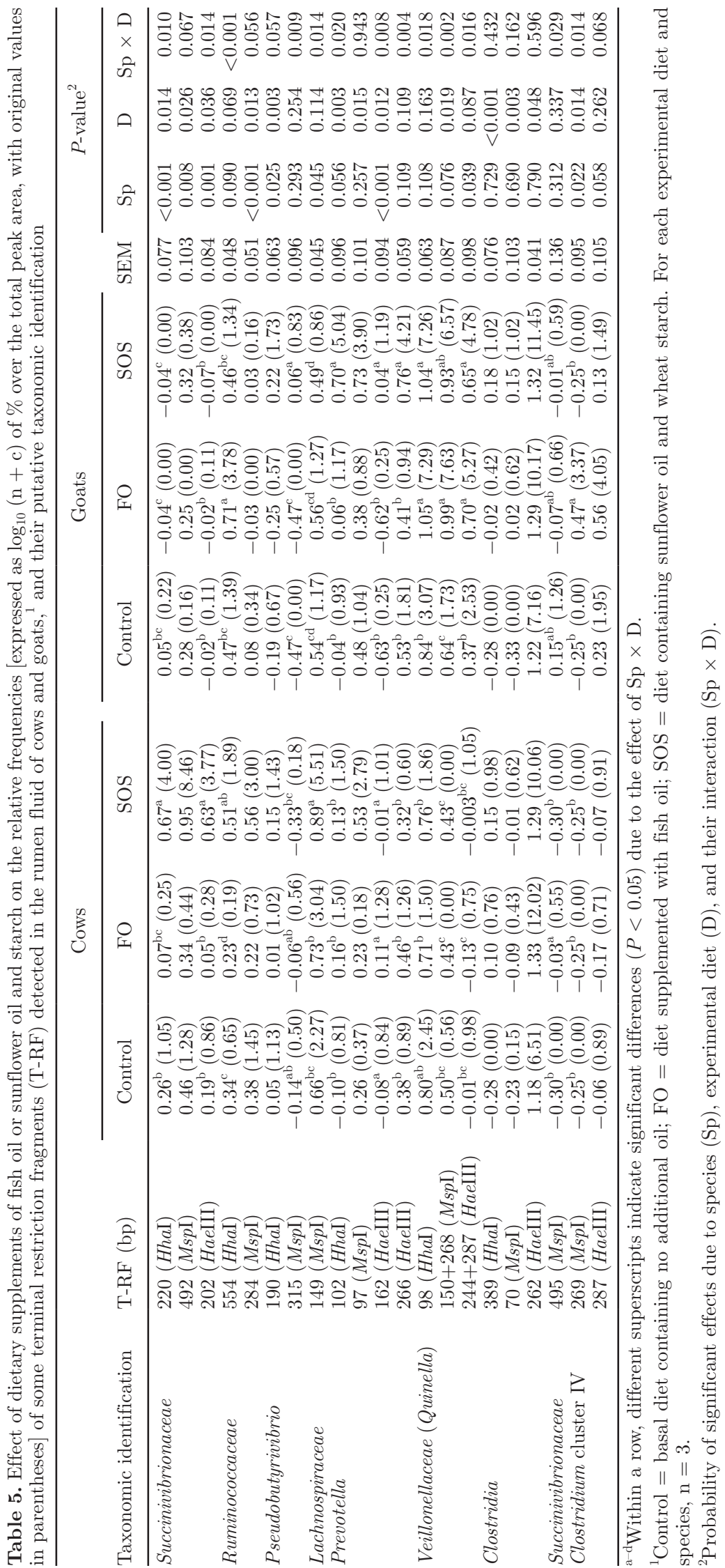




\section{Ruminal FA Metabolism}

Comparison of rumen FA concentrations (expressed as $\mathrm{g} / \mathrm{kg}$ of DM) in cows and goats fed the control diet provides evidence of interspecies differences in rumen $\mathrm{BH}$ that could be linked to differences in microbial composition. Thus, the much higher SFA concentration in the rumen fluid of goats than cows (in particular, 16:0 and 18:0), together with the lack of differences in total PUFA, would suggest more extensive $\mathrm{BH}$ in this species. However, when expressed as a percent of total FA (Supplemental Table S1; http://dx.doi.org/10.3168/ jds.2015-10292), the proportion of 18:0, total SFA, MUFA, and PUFA were similar in bovine and caprine. In other respects, the higher milk cis-9,trans-11 CLAto-trans-11 18:1 ratio observed in goats when compared with cows fed the control diet (Toral et al., 2015) might have derived from potential interspecies differences in intestinal FA digestibility or tissue lipid metabolism, rather than in ruminal BH (Chilliard et al., 2007; Shingfield et al., 2010a). Concerning the rumen microbiota, differences in the percentage of some specific OBCFA (e.g., 15:0, anteiso 15:0, 17:0, and iso 18:0) and similitudes in some others (e.g., iso 15:0, iso 16:0, iso 17:0, and anteiso 17:0), which derive mainly from de novo bacterial synthesis (Fievez et al., 2012), would support dissimilarities in the composition of the rumen microorganisms between cows and goats fed the control diet, as confirmed by T-RFLP. Furthermore, differences in the responses to lipid feeding of the ruminal microbiota of goats and cows hamper the identification of shared relevant bacteria associated with variations in the accumulation of specific $\mathrm{BH}$ intermediates. In other respects, species differences in OBCFA profile could also be due to differences in postruminal synthesis from the duodenum to the milk (Vlaeminck et al., 2015). Furthermore, the higher concentration of total FA observed in the rumen of goats compared with that of cows when both were fed the control diet might be related to interspecies differences in eating behavior, ruminal passage rates, and digestion kinetics (Duncan and Poppi, 2008), which might also account for differences in rumen FA concentrations. However, to our knowledge, no data have been published on direct comparisons in goats and cows of either the total FA concentration or the rumen FA profile, which underlines the novelty of these data and the need for additional and targeted research to explain the observed differences.

For all diets, rumen FA composition was characterized by low PUFA concentrations (in particular, 18:2n6 ), which might be explained by the sampling time in this experiment (before the morning meal) favoring a greater BH extent of the dietary FA (Loor et al., 2004). In any event, the effects of FO and SOS on rumen FA composition were consistent with reports in the literature with different rumen sampling times (e.g., means of 5 different time points in Boeckaert et al., 2008; $3 \mathrm{~h}$ after the meal in Toral et al., 2012; or $5 \mathrm{~h}$ after the meal in Zened et al., 2013a), supporting that, despite the relatively advanced stage of $\mathrm{BH}$, results seem to reflect diet-induced effects on this process. Furthermore, the links between rumen FA and daily milk FA (see below) suggest that morning sampling of rumen fluid gave an acceptable indication of the daily trend.

Indirect comparison of milk FA profiles from previous studies in goats and cows suggested similar effects on 18:0 concentrations when plant oil supplements are used (Chilliard et al., 2007), whereas the concentration of this FA was less affected in goats (Toral et al., 2014) than in cows (Offer et al., 1999; Shingfield et al., 2003) in response to fish oil. In the present study, however, dietinduced variations in rumen 18:0 contents were always more pronounced in goats, in agreement with milk FA composition in the same animals $[\mathrm{r}=0.875$ and 0.747 in goats $(\mathrm{n}=41)$ and cows $(\mathrm{n}=36)$, respectively, $P<$ 0.001; Toral et al., 2015]. In addition, greater increases in rumen 18:0 when fed SOS were observed in goats compared with cows (+209 vs. $+97 \%$, respectively), which suggests a more complete $\mathrm{BH}$ in goats of 18-carbon unsaturated FA from sunflower oil. On the other hand, a greater decrease in rumen 18:0 in goats than in cows when fed FO suggests a stronger inhibition of 18:0 formation due to FO (AbuGhazaleh et al., 2002; Loor et al., 2004; Shingfield et al., 2010b) in goats. This latter finding contrasts with indirect comparisons based on earlier works (Offer et al., 1999; Shingfield et al., 2003; Toral et al., 2014), although these might be biased by the scarcity of published studies in goats fed marine lipids and by differences in the percentage and composition of fish oils and composition of basal diets (e.g., use of hay-based diets in caprine vs. silage in bovine). In line with this different response between ruminant species, the $\mathrm{T}-\mathrm{RF}$ that changed similarly to rumen 18:0 concentration (namely that increased with SOS and decreased with FO) were not the same in bovine and caprine. Bacterial populations compatible with these T-RF, which were potentially linked to 18:1 saturation, would belong to Ruminococcaceae in cows and Pseudobutryrivibrio in goats. Microorganisms of both groups have been previously associated with 18:0 accumulation in the rumen of steers (Huws et al., 2011) and sheep (Castro-Carrera et al., 2014), whereas so far no data are available in goats.

Diet-induced variations in total trans 18:1 concentration were also more pronounced in goat rumen fluid, whereas milk FA responses had been observed to be greater in cows (Toral et al., 2015). This might be speculated to be due to interspecies differences in $\mathrm{BH}$ 
kinetics (without ruling out potential sampling time constraints), intestinal digestibility, or in the mammary or body tissue uptake and utilization of these trans FA. On the other hand, effects of dietary treatments on the trans 18:1 isomer profile were relatively consistent in the rumen and milk of cows (e.g., $r=0.923$ and 0.921 for concentrations of trans-10 18:1 and trans-11 18:1, respectively; $P<0.001 ; \mathrm{n}=36)$ and goats $(\mathrm{r}=0.858$ and 0.917 for the same correlations; $P<0.001$; $\mathrm{n}=41$; Toral et al., 2015), even though samples might not be fully representative of rumen digestion over $24 \mathrm{~h}$. Thus, results from both types of samples (i.e., milk and rumen) indicated that SOS diet altered ruminal BH and resulted in trans-10 18:1 replacing trans-11 18:1 as the major intermediate in cows, in agreement with earlier studies examining the effect of high-starch diets and plant oils on cow milk or rumen digesta (e.g., Loor et al., 2005; Zened et al., 2013a). The fact that this shift was larger in the cow than in the goat suggests that $\mathrm{BH}$ pathways in caprine are more stable and robust in response to high-starch diets and plant oils (Chilliard et al., 2007; Shingfield et al., 2010a), which may contribute to explain interspecies differences in the propensity to MFD on this type of diets (Roy et al., 2006; Bernard et al., 2009; Toral et al., 2015). Consistent with changes in rumen trans-10 18:1 concentrations, SOS increased the relative abundance of some T-RF compatible with species of Lachnospiraceae in cows and of Prevotella in goats, suggesting a potential relationship of these fragments with the trans-10 shift. In cows, species of both bacterial groups have been associated with lipid metabolism (Boeckaert et al., 2008; Huws et al., 2011) and strains of Prevotella were more abundant with a highstarch diet supplemented with sunflower oil (Zened et al., 2013b). Nonetheless, the available information on the relationship between these groups and dietary lipid $\mathrm{BH}$ in goats is very limited (Zhu et al., 2012).

Regarding specific $\mathrm{BH}$ intermediates that may be responsible for SOS-induced MFD, cows fed this diet showed the greatest ruminal content of trans-10, cis-12 CLA, which is remarkable because, as previously stated, the total FA concentration in the rumen fluid of cows was $60 \%$ lower than in goats. The trans-10, cis- 12 CLA is the only $\mathrm{BH}$ metabolite shown unequivocally to inhibit milk fat synthesis (Shingfield and Griinari, 2007; Bauman et al., 2011), and the mammary gland of bovine is much more sensitive to its antilipogenic effect than that of caprine (Chilliard et al., 2014). In any case, as discussed in the companion paper (Toral et al., 2015), changes in the concentration of this CLA isomer in milk did not, in isolation, explain the extent of MFD in cows fed SOS, and other rumen BH intermediates (such as cis-10,trans-12 CLA, trans-10 18:1, or other unidentified FA) would also be implicated. Furthermore, without a specific HPLC analysis, results on trans-10,cis-12 CLA should be taken with caution because our GC conditions might cause the co-elution of minor CLA isomers and other low abundant intermediates. This fact may also be behind the observed increase in this FA in the rumen fluid of cows fed FO, which is not a common observation in digesta samples (e.g., Shingfield et al., 2003, 2010b; Loor et al., 2004). Something similar occurred with trans-9,cis-11 CLA concentrations, another $\mathrm{BH}$ intermediate that has been reported as a potential milk fat inhibitor in cows (Perfield et al., 2007); yet, its diet-induced proportion in milk is often lower than the level of enrichment used to demonstrate antilipogenic effects (Roy et al., 2006; Perfield et al., 2007; Bichi et al., 2013).

Induction of MFD with diets containing marine oils has often been related to the joint action of decreases in 18:0 availability and increases in trans 18:1 contributing to limit the synthesis of milk fat with an adequate fluidity to be secreted by mammary epithelial cells (Shingfield and Griinari, 2007). However, notwithstanding the greater extent of changes in these FA in the rumen of goats, these animals experienced a lower MFD than cows $(21$ vs. $30 \%$ reduction in milk fat content, respectively; Toral et al., 2015). This might point to either a major contribution of other FA to maintain milk fat fluidity, such as short-chain FA de novo synthesized in the mammary gland, or other mechanisms explaining that goats are less prone to this syndrome (Bernard et al., 2010; Toral et al., 2014). In relation to specificities in the bacterial community composition, this response was linked to FO-induced increments of different T-RF in each species, such as those compatible with bacteria of Succinivibrionaceae in cows and Clostridium cluster IV in goats. Although the role of these microorganisms in lipid metabolism is still uncertain, species of Succinivibrionaceae have been related to rumen $\mathrm{BH}$ in ewes (Castro-Carrera et al., 2014), and Clostridium cluster IV has been recently associated with BH of n-3 PUFA in cattle (Petri et al., 2014).

As mentioned previously, few individual FA have been directly associated with diet-induced MFD (Shingfield and Griinari, 2007; Bauman et al., 2011). In most cases, however, reports on their biological activity are still equivocal (e.g., trans-10 18:1; Shingfield et al., 2010a) and changes in their rumen and milk concentrations may not fully explain MFD (as mentioned for trans10,cis-12 CLA or trans-9,cis-11 CLA; Roy et al., 2006; Boeckaert et al., 2008; Bichi et al., 2013). Thus, other FA may also be involved and account for this syndrome. For example, recent studies have indicated that cis-11 $^{-1}$ 18:1, a FA commonly found in ruminant feedstuffs, was 
able to alter lipogenesis in bovine adipocyte cultures (Burns et al., 2012) and was associated with a decrease in milk fat content in goats fed FO (Bernard et al., 2015). In this regard, the FO diet increased the accumulation of this 18:1 isomer in the rumen, particularly in goats (5-fold) but also in cows (3-fold), whereas the greatest concentration in milk fat was observed in the latter (Toral et al., 2015), which would oblige to further investigate its potential role in mammary lipogenesis. Furthermore, the role of $\mathrm{BH}$ intermediates from longchain FA, such as 20- and 22-carbon FA (in particular those containing a trans-10 double bond), on the observed effects of FO on milk fat cannot be excluded (Toral et al., 2015).

Intermediate metabolites derived from sequential hydration and oxidation of dietary FA in the rumen, as alternative pathways (Jenkins et al., 2006), might also have biological activity in ruminants (Raphael et al., 2014), but their effect on milk fat synthesis has not been characterized yet. Concentrations of 10-O-16:0, 10-O-18:0, and 13-O-18:0 were particularly enhanced with FO, which is in agreement with earlier measurements in cows and ewes (Shingfield et al., 2010b; Toral et al., 2010, 2012). In the present study, the detection of these oxylipids could have been favored by the sampling time (i.e., after an overnight period without concentrate distribution), because they seem to be end products of ruminal FA metabolism (Jenkins et al., 2006). Concerning rumen microbiota, specific T-RF that might be associated with hydration would correspond to Veillonellaceae in goats and to Clostridia in both species. Studies with sheep (Belenguer et al., 2010; Toral et al., 2012) suggested a putative participation of species of Veillonellaceae, such as Quinella ovalis, in this process. With respect to Clostridia, this is a broad and diverse group that includes microorganisms potentially related to lipid metabolism (Boeckaert et al., 2008; Huws et al., 2015), such as those compatible with the 389-bp T-RF detected with $H h a \mathrm{I}$, which has been previously shown to increase with marine lipids in ewes (Belenguer et al., 2010; Toral et al., 2012).

As discussed for 18:0 and trans-18:1, the tendency toward greater effects of FO on 10-O-18:0 concentration in goats than in cows would further support a more potent effect of this supplement in the rumen of goats, whereas increases in keto acids in milk were more evident in cows (Toral et al., 2015). Overall, the reasons for the inconsistent results between diet-induced changes in rumen and milk FA are not readily apparent but might be related, despite the possible interaction with the rumen sampling time, to interspecies differences in FA digestion and transport, and body tissues or mammary lipid metabolism (Chilliard et al., 2007; Shingfield et al., 2010a).

\section{CONCLUSIONS}

Direct comparison of ruminal responses to diets inducing MFD demonstrates relevant species-by-diet interactions on the rumen FA composition and bacterial community. However, changes in some ruminal fermentation characteristics due to FO or SOS (e.g., decreases in acetate-to-propionate ratio) were similar in cows and goats. The main alterations in ruminal $\mathrm{BH}$ pathways potentially responsible for MFD on the SOS treatment (i.e., the trans-10 shift and related increases in trans-10,cis-12 CLA concentration) tend to be more pronounced in cows than in goats, whereas changes linked to FO-induced MFD (e.g., decreases in 18:0 and increases in total trans-18:1 accumulation) are more evident in caprine rumen fluid. Results support the initial hypothesis that distinct ruminal mechanisms lead to each type of diet-induced MFD, and may also explain the unexpected susceptibility of dairy goats (although less marked than in cows) to the negative effect of $\mathrm{FO}$ on milk fat content. The bacterial populations affected by SOS or FO diets differ between cows and goats, in agreement with species-specific microbial community structures. Furthermore, most relevant variations in microbial groups correspond to as yet uncultured bacteria and suggest that these microorganisms may play a predominant role in the ruminal lipid metabolism in both cows and goats.

\section{ACKNOWLEDGMENTS}

This study was supported by INRA (UMR1213; France) and the Spanish Ministry of Economy and Competitiveness (MINECO; AGL2014-54587). P. G. Toral was granted a postdoctoral fellowship from Fundación Alfonso Martín Escudero (Madrid, Spain) and a research contract from the MINECO (Juan de la Cierva program). The authors gratefully acknowledge the staff of UERT 1354 (INRA, France) for the diligent care of the experimental animals, D. Bany, C. Labonne, and M. Tourret from UMR 1213 (INRA, France) for assistance in sampling collection, the staff of the Instituto de Ganadería de Montaña (CSIC; León, Spain) for assistance in laboratory analysis, and C. Martin and M. Sylberberg from UMR 213 (INRA, France) for helpful discussions. Thanks are also given to Neil R. McEwan from the Institute of Biological, Environmental and Rural Sciences (IBERS) of Aberystwyth University (Aberystwyth, UK) for kindly revising the manuscript.

\section{REFERENCES}

Abdo, Z., U. M. E. Schuette, S. J. Bent, C. J. Williams, L. J. Forney, and P. Joyce. 2006. Statistical methods for characterizing diversity of microbial communities by analysis of terminal restriction frag- 
ment length polymorphisms of $16 \mathrm{~S}$ rRNA genes. Environ. Microbiol. 8:929-938.

AbuGhazaleh, A. A., D. J. Schingoethe, A. R. Hippen, K. F. Kalscheur, and L. A. Whitlock. 2002. Fatty acid profiles of milk and rumen digesta from cows fed fish oil, extruded soybeans or their blend. J. Dairy Sci. 85:2266-2276.

Anderson, M. J. 2001. A new method for non-parametric multivariate analysis of variance. Austral Ecol. 26:32-46.

Bateman, H. G., and T. C. Jenkins. 1998. Influence of soybean oil in high fiber diets fed to nonlactating cows on ruminal unsaturated fatty acids and nutrient digestibility. J. Dairy Sci. 81:2451-2458.

Bauman, D. E., and J. M. Griinari. 2001. Regulation and nutritional manipulation of milk fat: Low-fat milk syndrome. Livest. Prod. Sci. 70:15-29.

Bauman, D. E., K. J. Harvatine, and A. L. Lock. 2011. Nutrigenomics, rumen-derived bioactive fatty acids, and the regulation of milk fat synthesis. Annu. Rev. Nutr. 31:299-319.

Beauchemin, K. A., M. Kreuzer, F. O'Mara, and T. A. McAllister. 2008. Nutritional management for enteric methane abatement: A review. Aust. J. Exp. Agric. 48:21-27.

Bekele, A. Z., S. Koike, and Y. Kobayashi. 2010. Genetic diversity and diet specificity of ruminal Prevotella revealed by $16 \mathrm{~S}$ rRNA genebased analysis. FEMS Microbiol. Lett. 305:49-57.

Belenguer, A., P. G. Toral, P. Frutos, and G. Hervás. 2010. Changes in the rumen bacterial community in response to sunflower oil and fish oil supplements in the diet of dairy sheep. J. Dairy Sci. 93:3275-3286.

Bernard, L., C. Leroux, J. Rouel, C. Delavaud, K. J. Shingfield, and Y. Chilliard. 2015. Effect of extruded linseeds alone or in combination with fish oil on intake, milk production, plasma metabolite concentrations and milk fatty acid composition in lactating goats. Animal 9:810-821.

Bernard, L., J. Mouriot, J. Rouel, F. Glasser, P. Capitan, E. PujosGuillot, J. M. Chardigny, and Y. Chilliard. 2010. Effects of fish oil and starch added to a diet containing sunflower-seed oil on dairy goat performance, milk fatty acid composition and in vivo $\Delta$ 9-desaturation of $\left[{ }^{13} \mathrm{C}\right]$ vaccenic acid. Br. J. Nutr. 104:346-354.

Bernard, L., K. J. Shingfield, J. Rouel, A. Ferlay, and Y. Chilliard. 2009. Effect of plant oils in the diet on performance and milk fatty acid composition in goats fed diets based on grass hay or maize silage. Br. J. Nutr. 101:213-224.

Bichi, E., G. Hervás, P. G. Toral, J. J. Loor, and P. Frutos. 2013. Milk fat depression induced by dietary marine algae in dairy ewes: Persistency of milk fatty acid composition and animal performance responses. J. Dairy Sci. 96:524-532.

Boeckaert, C., B. Vlaeminck, V. Fievez, L. Maignien, J. Dijkstra, and N. Boon. 2008. Accumulation of trans C-18:1 fatty acids in the rumen after dietary algal supplementation is associated with changes in the Butyrivibrio community. Appl. Environ. Microbiol. 74:6923-6930.

Burns, T. A., A. K. G. Kadegowda, S. K. Duckett, S. L. Pratt, and T. C. Jenkins. 2012. Palmitoleic (16:1 cis-9) and cis-vaccenic (18:1 cis-11) acid alter lipogenesis in bovine adipocyte cultures. Lipids 47:1143-1153.

Castro-Carrera, T., P. G. Toral, P. Frutos, N. R. McEwan, G. Hervás, L. Abecia, E. Pinloche, S. E. Girdwood, and A. Belenguer. 2014. Rumen bacterial community evaluated by 454 pyrosequencing and terminal restriction fragment length polymorphism analyses in dairy sheep fed marine algae. J. Dairy Sci. 97:1661-1669.

Chilliard, Y., F. Glasser, A. Ferlay, L. Bernard, J. Rouel, and M. Doreau. 2007. Diet, rumen biohydrogenation and nutritional quality of cow and goat milk fat. Eur. J. Lipid Sci. Technol. 109:828855 .

Chilliard, Y., P. G. Toral, K. J. Shingfield, J. Rouel, C. Leroux, and L. Bernard. 2014. Effects of diet and physiological factors on milk fat synthesis, milk fat composition and lipolysis in the goat. A short review. Small Rumin. Res. 122:31-37.

Cole, J. R., Q. Wang, J. Fish, B. Chai, D. M. McGarrell, Y. Sun, C. Titus Brown, A. Porras-Alfaro, C. A. Kuske, and J. M. Tiedje. 2014. Ribosomal database project: Data and tools for high throughput rRNA analysis. Nucleic Acids Res. 42:D633-D642.
Doreau, M., and Y. Chilliard. 1997. Effects of ruminal or postruminal fish oil supplementation on intake and digestion in dairy cows. Reprod. Nutr. Dev. 37:113-124.

Duncan, A. J., and D. P. Poppi. 2008. Nutritional ecology of grazing and browsing ruminants. Pages 89-116 in The Ecology of Browsing and Grazing. Ecological Studies Vol., 195. I. J. Gordon, and H. H. T. Prins, ed. Springer-Verlag, Berlin, Germany.

Fievez, V., E. Colman, J. M. Castro-Montoya, I. Stefanov, and B. Vlaeminck. 2012. Milk odd- and branched-chain fatty acids as biomarkers of rumen function-An update. Anim. Feed Sci. Technol. 172:51-65.

Frutos, P., G. Hervás, F. J. Giráldez, and A. R. Mantecón. 2004. An in vitro study on the ability of polyethylene glycol to inhibit the effect of quebracho tannins and tannic acid on rumen fermentation in sheep, goats, cows, and deer. Aust. J. Agric. Res. 55:1125-1132.

Fuentes, M. C., S. Calsamiglia, P. Cardozo, and B. Vlaeminck. 2009. Effect of $\mathrm{pH}$ and level of concentrate in the diet on the production of biohydrogenation intermediates in a dual-flow continuous culture. J. Dairy Sci. 92:4456-4466.

Hill, T. C. J., K. A. Walsh, J. A. Harris, and B. F. Moffett. 2003. Using ecological diversity measures with bacterial communities. FEMS Microbiol. Ecol. 43:1-11.

Huws, S. A., E. J. Kim, S. J. S. Cameron, S. E. Girdwood, L. Davies, J. Tweed, H. Valin, and N. D. Scollan. 2015. Characterization of the rumen lipidome and microbiome of steers fed a diet supplemented with flax and echium oil. Microb. Biotechnol. 8:331-341.

Huws, S. A., E. J. Kim, M. R. F. Lee, M. B. Scott, J. K. S. Tweed, E. Pinloche, R. J. Wallace, and N. D. Scollan. 2011. As yet uncultured bacteria phylogenetically classified as Prevotella, Lachnospiraceae incertae sedis and unclassified Bacteroidales, Clostridiales and Ruminococcaceae may play a predominant role in ruminal biohydrogenation. Environ. Microbiol. 13:1500-1512.

Jenkins, T. C., A. A. AbuGhazaleh, S. Freeman, and E. J. Thies. 2006. The production of 10-hydroxystearic and 10-ketostearic acids is an alternative route of oleic acid transformation by the ruminal microbiota in cattle. J. Nutr. 136:926-931.

Kaps, M., and W. R. Lamberson. 2009. Biostatistics for Animal Science, 2nd ed. CABI Publishing, Wallingford, UK.

Lee, H. J., J. Y. Jung, Y. K. Oh, S. S. Lee, E. L. Madsen, and C. O. Jeon. 2012. Comparative survey of rumen microbial communities and metabolites across one caprine and three bovine groups, using bar-coded pyrosequencing and $\mathrm{H}-1$ nuclear magnetic resonance spectroscopy. Appl. Environ. Microbiol. 78:5983-5993.

Ley, R. E., M. Hamady, C. Lozupone, P. J. Turnbaugh, R. R. Ramey, J. S. Bircher, M. L. Schlegel, T. A. Tucker, M. D. Schrenzel, R. Knight, and J. I. Gordon. 2008. Evolution of mammals and their gut microbes. Science 320:1647-1651.

Li, F., X. J. Yang, Y. C. Cao, S. X. Li, J. H. Yao, Z. J. Li, and F. F. Sun. 2014. Effects of dietary effective fiber to rumen degradable starch ratios on the risk of sub-acute ruminal acidosis and rumen content fatty acids composition in dairy goat. Anim. Feed Sci. Technol. 189:54-62

Loor, J. J., A. Ferlay, A. Ollier, K. Ueda, M. Doreau, and Y. Chilliard. 2005. High-concentrate diets and polyunsaturated oils alter trans and conjugated isomers in bovine rumen, blood, and milk. J. Dairy Sci. 88:3986-3999.

Loor, J. J., K. Ueda, A. Ferlay, Y. Chilliard, and M. Doreau. 2004. Short communication: Diurnal profiles of conjugated linoleic acids and trans fatty acids in ruminal fluid from cows fed a high concentrate diet supplemented with fish oil, linseed oil, or sunflower oil. J. Dairy Sci. 87:2468-2471.

Moon, Y. H., J. U. Ok, S. J. Lee, J. K. Ha, and S. S. Lee. 2010. A comparative study on the rumen microbial populations, hydrolytic enzyme activities and dry matter degradability between different species of ruminant. Anim. Sci. J. 81:642-647.

Offer, N. W., M. Marsden, J. Dixon, B. K. Speake, and F. E. Thacker. 1999. Effect of dietary fat supplements on levels of n-3 poly-unsaturated fatty acids, trans acids and conjugated linoleic acid in bovine milk. Anim. Sci. 69:613-625.

Perfield, J. W., A. L. Lock, J. M. Griinari, A. Sæbø, P. Delmonte, D. A. Dwyer, and D. E. Bauman. 2007. Trans-9,cis-11 conjugated 
linoleic acid reduces milk fat synthesis in lactating dairy cows. J. Dairy Sci. 90:2211-2218.

Petri, R. M., C. Mapiye, M. E. R. Dugan, and T. A. McAllister. 2014. Subcutaneous adipose fatty acid profiles and related rumen bacterial populations of steers fed red clover or grass hay diets containing flax or sunflower-seed. PLoS ONE 9:e104167.

Ramos-Morales, E., A. Arco-Pérez, A. I. Martín-García, D. R. YáñezRuiz, P. Frutos, and G. Hervás. 2014. Use of stomach tubing as an alternative to rumen cannulation to study ruminal fermentation and microbiota in sheep and goats. Anim. Feed Sci. Technol. 198:57-66.

Raphael, W., L. Halbert, G. A. Contreras, and L. M. Sordillo. 2014. Association between polyunsaturated fatty acid-derived oxylipid biosynthesis and leukocyte inflammatory marker expression in periparturient dairy cows. J. Dairy Sci. 97:3615-3625.

Roy, A., A. Ferlay, K. J. Shingfield, and Y. Chilliard. 2006. Examination of the persistency of milk fatty acid composition responses to plant oils in cows given different basal diets, with particular emphasis on trans-C18:1 fatty acids and isomers of conjugated linoleic acid. Anim. Sci. 82:479-492.

Russell, J. B., and R. B. Hespell. 1981. Microbial rumen fermentation. J. Dairy Sci. 64:1153-1169.

Shingfield, K. J., S. Ahvenjärvi, V. Toivonen, A. Äröla, K. V. V. Nurmela, P. Huhtanen, and J. M. Griinari. 2003. Effect of dietary fish oil on biohydrogenation of fatty acids and milk fatty acid content in cows. Anim. Sci. 77:165-179.

Shingfield, K. J., S. Ahvenjärvi, V. Toivonen, A. Vanhatalo, P. Huhtanen, and J. M. Griinari. 2008. Effect of incremental levels of sunflower-seed oil in the diet on ruminal lipid metabolism in lactating cows. Br. J. Nutr. 99:971-983.

Shingfield, K. J., L. Bernard, C. Leroux, and Y. Chilliard. 2010a. Role of trans fatty acids in the nutritional regulation of mammary lipogenesis in ruminants. Animal 4:1140-1166.

Shingfield, K. J., and J. M. Griinari. 2007. Role of biohydrogenation intermediates in milk fat depression. Eur. J. Lipid Sci. Technol. 109:799-816.

Shingfield, K. J., M. R. F. Lee, D. J. Humphries, N. D. Scollan, V. Toivonen, and C. K. Reynolds. 2010b. Effect of incremental amounts of fish oil in the diet on ruminal lipid metabolism in growing steers. Br. J. Nutr. 104:56-66.

Toral, P. G., A. Belenguer, K. J. Shingfield, G. Hervás, V. Toivonen, and P. Frutos. 2012. Fatty acid composition and bacterial community changes in the rumen fluid of lactating sheep fed sunflower oil plus incremental levels of marine algae. J. Dairy Sci. 95:794-806.

Toral, P. G., Y. Chilliard, J. Rouel, H. Leskinen, K. J. Shingfield, and L. Bernard. 2015. Comparison of the nutritional regulation of milk fat secretion and composition in cows and goats. J. Dairy Sci. 98:7277-7297.

Toral, P. G., J. Rouel, L. Bernard, and Y. Chilliard. 2014. Interaction between fish oil and plant oils or starchy concentrates in the diet: Effects on dairy performance and milk fatty acid composition in goats. Anim. Feed Sci. Technol. 198:67-82.

Toral, P. G., K. J. Shingfield, G. Hervás, V. Toivonen, and P. Frutos. 2010. Effect of fish oil and sunflower oil on rumen fermentation characteristics and fatty acid composition of digesta in ewes fed a high concentrate diet. J. Dairy Sci. 93:4804-4817.

Vlaeminck, B., R. Gervais, M. M. Rahman, F. Gadeyne, M. Gorniak, M. Doreau, and V. Fievez. 2015. Postruminal synthesis modifies the odd- and branched-chain fatty acid profile from the duodenum to milk. J. Dairy Sci. 98:4829-4840.

Zened, A., S. Combes, L. Cauquil, J. Mariette, C. Klopp, O. Bouchez, A. Troegeler-Meynadier, and F. Enjalbert. 2013b. Microbial ecology of the rumen evaluated by 454 GS FLX pyrosequencing is affected by starch and oil supplementation of diets. FEMS Microbiol. Ecol. 83:504-514.

Zened, A., F. Enjalbert, M. C. Nicot, and A. Troegeler-Meynadier. 2013a. Starch plus sunflower oil addition to the diet of dry dairy cows results in a trans-11 to trans-10 shift of biohydrogenation. J. Dairy Sci. 96:451-459.

Zhu, Z., S. Mao, and W. Zhu. 2012. Effects of ruminal infusion of garlic oil on fermentation dynamics, fatty acid profile and abundance of bacteria involved in biohydrogenation in rumen of goats. Asianaustralas. J. Anim. Sci. 25:962-970. 